\title{
Potassium Transport by the Isolated Perfused Kidney
}

\author{
Patricio Silva, Brian D. Ross, Alan N. Charney, \\ Anatole Besarab, and Franklin H. Epstein \\ From the Department of Medicine and Thorndike Laboratory, Harvard \\ Medical School and Beth Israel Hospital, Boston, Massachusetts 02215
}

A B S T R A C T Rat kidneys perfused outside of the body with an artificial medium are able to increase their fractional excretion of potassium in response to a rising concentration of potassium in the medium but never show net secretion of potassium. By contrast, isolated perfused kidneys from chronically potassiumloaded rats regularly secrete potassium in excess of the amount filtered. Ouabain completely blocks the secretion of potassium by these isolated kidneys, suggesting that Na-K-ATPase mediates potassium secretion by potassium-adapted rats. Neither sodium deprivation, pretreatment with deoxycorticosterone, nor pretreatment with methylprednisolone prepared the kidney to secrete potassium, despite stimulation of Na-K-ATPase activity in cortex or outer medulla. Potassium loading was the only maneuver tested that increased the activity of Na-K-ATPase in the inner medulla (white papilla) and also produced potassium secretion by the isolated kidney. Surgical ablation of the papilla abolished the net secretion of potassium normally seen in perfused kidneys of potassium-adapted rats, thus underlining the importance of the papilla in the process of potassium adaptation.

\section{INTRODUCTION}

Animals subjected to chronic potassium loading rapidly develop the ability to avoid hyperkalemia by excreting large amounts of potassium into the urine. It has not been clear whether the kidney itself is changed during the process of potassium adaptation or whether the enhanced excretory response is the secondary result of extrarenal influences playing upon the kidney and elicited by the administration of potassium to the whole animal.

In the present experiments we have examined the phenomenon of potassium adaptation by perfusing the rat kidney in vitro with an artificial medium utilizing the technique of isolated kidney perfusion (1). Isolated kidneys removed from chronically potassium-loaded rats regularly demonstrate the ability to secrete unusually

Received for publication 7 February 1975 and in revised form 12 May 1975. large amounts of potassium into the urine, an intrinsic adaptation connected with the development of a high specific activity of Na-K-ATPase in the renal papilla, presumably in the cells lining the collecting ducts. The importance of the collecting ducts is further underlined by the finding that surgical removal of the white papilla of rats eliminates net secretion of potassium by the perfused kidneys.

\section{METHODS}

Male Sprague-Dawley rats, weighing $270-480 \mathrm{~g}$, were used in all the experiments. Control animals on a normal potassium diet received Purina rat chow (Ralston Purina Co., St. Louis, Mo.) and were allowed free access to water. Animals fed a diet with a high content of potassium were given $0.1 \mathrm{M} \mathrm{KCl}$ to drink and a diet with the following composition: sucrose $43 \%$, casein $26 \%$, lard $9 \%$, corn oil $4 \%$, vitamin diet fortification mixture $1.8 \%$, normal mineral mixture $2.7 \%, \mathrm{KCl} 13 \%$, and $\mathrm{NaCl} 0.5 \%$, for a period of 7 days before sacrifice. A third group of rats were fed a normal diet, allowed free access to water, and in addition received methylprednisolone (Depo-Medro, The Upjohn Company, Kalamazoo, Mich.) injected subcutaneously as an aqueous suspension in a dose of $3 \mathrm{mg} / 100 \mathrm{~g}$ per day for 3 days. A fourth group of rats fed Purina rat chow and tap water received deoxycorticosterone acetate (DOCA, ${ }^{1}$ Organon Inc., West Orange, N. J.), injected subcutaneously as a suspension in sesame oil in a dose of $0.5 \mathrm{mg} / 100 \mathrm{~g}$ for 7 days. A fifth group was comprised of rats fed a synthetic sodium-free diet, similar in all respects to that of group 2, with tap water for a period of 7 days. In a sixth and final group of rats fed a high-potassium diet, papillectomy was performed with the aid of pituitary forceps through a small incision in the lower pole of the kidney 2 wk before sacrifice. ${ }^{2}$

Isolated kidney perfusions. The kidneys obtained from donor rats belonging to each of the six experimental groups were perfused according to the technique of NishiitsutsujiUwo et al. (2), as modified by Ross et al. (1). The animals were anesthetized with $60 \mathrm{mg} / \mathrm{kg}$ pentobarbital i.p., and $50 \mathrm{mg}$ mannitol/100 $\mathrm{g}$, and $1,000 \mathrm{U}$ heparin sodium were injected into the femoral vein. The abdomen was

${ }^{1}$ Abbreviation used in this paper: DOCA, deoxycorticosterone acetate.

${ }^{2}$ The renal papillectomy technique described here was developed by Dr. Lester A. Klein, Chief of Urology at the Beth Israel Hospital, to whom the authors gratefully extend their appreciation. 
opened, and a polyethylene PE10 catheter was placed into the ureter, a plastic cannula was placed in the inferior vena cava, and a glass cannulae was inserted into the superior mesenteric artery and threaded through the aorta into the right renal artery. Perfusion medium, prepared initially as a $10 \%$ bovine albumin solution, was diluted to a final concentration of $6.5-6.8 \%$ and contained $(\mathrm{mM})$ $\mathrm{Na} 145 ; \mathrm{K} 4.5-5.5 ; \mathrm{Ca} 1.25 ; \mathrm{Mg} 1.2$; bicarbonate $25 ; \mathrm{Cl}$ 100 ; phosphate 1.2 ; sulfate 0.8 ; at a $\mathrm{pH}$ of 7.4 when gassed with $5 \% \quad \mathrm{CO}_{2}-95 \% \quad \mathrm{O}_{2}$. The medium was recirculated at a pressure of $110 / 90 \mathrm{~mm} \mathrm{Hg}$ distal to the tip of the arterial cannula at a mean flow of $36 \mathrm{ml} / \mathrm{min} .5 \mathrm{mM}$ Glucose was used as the sole exogenous substrate.

After an initial 15-20-min equilibration period, three or more 5-min control clearance periods were collected. These were followed by different experimental maneuvers. In some experiments $0.8 \mathrm{ml}$ of a $0.154 \mathrm{M} \mathrm{KCl}$ solution was added to the recirculating medium at the end of each of five consecutive clearance periods, with the purpose of increasing perfusion medium potassium concentration. An average concentration of $12 \mathrm{mM}$ potassium/liter perfusion medium was thus attained at the end of each experiment. In other experiments ouabain ( $\mathrm{K}$ and $\mathrm{K}$ Laboratories, Inc., Plainview, N. Y.) was added either immediately after the control periods or after the potassium supplementation to a final concentration of $4 \mathrm{mM}$. Glomerular filtration rate was determined with $\left[{ }^{14} \mathrm{C}\right]$ inulin (New England Nuclear, Boston, Mass.). Sodium and potassium were measured in an IL 143 flame photometer (Instrumentation Laboratory, Inc., Lexington, Mass.). Results are expressed for the control period as the average of clearance period at designated time intervals (generally at zero time just before the start of the experimental period) and for the experimental period as the value obtained at a fixed time interval after the addition of potassium (usually $30 \mathrm{~min}$ ). When ouabain was added, the average of the clearance periods given is for the values seen after the initial vasoconstrictive effects of the drug had abated (3).

Sodium-potassium actizated ATPase assay. Different animals from those used as kidney donors but otherwise similarly prepared were used for Na-K-ATPase assay. Under light ether anesthesia the kidneys were removed and placed in ice-cold $0.9 \%$ saline. The excised kidneys were then cleaned, stripped of their capsules, and weighed. They were hemisected in a sagittal plane, and the cortex, outer medulla, and white medulla and papilla were identified and dissected with a pair of fine scissors. The tissue adjacent to the borders was discarded, and the samples were returned to the ice-cold saline. When all kidneys had been so dissected, the pieces of cortex, outer medulla, and white medulla and papilla were blotted on filter paper, weighed, and then homogenized with a Teflon pestle in a glass homogenizer and immersed in ice in a $20: 1$ (vol/wt) solution containing $0.25 \mathrm{M}$ sucrose, $6 \mathrm{mM}$ EDTA, $20 \mathrm{mM}$ imidazole, and $2.4 \mathrm{mM}$ sodium deoxycholate (added just before use), $\mathrm{pH}$ 6.8. The homogenate was filtered through a double layer of gauze and, after $45 \mathrm{~min}$, assayed for enzyme activity. Na-K-ATPase activity was defined as the difference between the inorganic phosphate liberated in the presence and absence of potassium, corrected for spontaneous nonenzymatic breakdown of ATP. Total ATPase was determined in a $5-\mathrm{ml}$ reaction mixture containing $\mathrm{NaCl} 100 \mathrm{mM}, \mathrm{KCl} 20 \mathrm{mM}$, imidazole buffer, $\mathrm{pH} 7.8,10$ $\mathrm{mM}, \mathrm{MgCl}_{2} 6 \mathrm{mM}$, ATP disodium salt (Sigma Chemical Corp., St. Louis, Mo.) $6 \mathrm{mM}$, and enzyme suspension enough to bring the final protein concentration to 0.005 $0.01 \mathrm{mg} / \mathrm{ml}$. The reaction was started by the addition of
$1 \mathrm{ml}$ of ATP and $\mathrm{MgCl}_{2}$, shaken in a water bath at $37^{\circ} \mathrm{C}$ for $15 \mathrm{~min}$, and stopped by the addition of $1 \mathrm{ml}$ of ice-cold $35 \%$ trichloroacetic acid (wt/vol). After centrifugation, the inorganic phosphate liberated was measured by the method of Fiske and SubbaRow (4), and the optical density was read at $660 \mathrm{~nm}$ in a $300 \mathrm{~N}$ Gilford spectrophotometer equipped with a quick sampling cell (Gilford Instrument Laboratories, Inc., Oberlin, Ohio). The activity of the enzyme was expressed as micromoles of inorganic phosphate liberated per milligram of protein per hour.

Determination of protein in the homogenates and in the perfusion medium was carried out according to the method of Lowry et al. (5) with crystalline bovine albumin dissolved either in homogenizing medium or in a solution with an ionic composition equivalent to the recirculating medium as standard.

Results are expressed as the mean \pm standard deviation. Statistical analysis of the data was made with Student's $t$ test or paired $t$ test wherever applicable.

\section{RESULTS}

Potassium excretion by isolated perfused kidneys from normal rats (Table I, Fig. 1). The rate of potassium excretion in isolated perfused kidneys obtained from control rats on a diet normal in potassium averaged $1.3 \pm 0.5 \mu \mathrm{eq} / \mathrm{min}$. This value was found to be stable for periods of time up to $120 \mathrm{~min}$ and is in good agreement with that found in live animals. The ratio of urine to plasma potassium was $5.8 \pm 3.0$. In these normal kidneys fractional excretion of potassium averaged $0.42 \pm$ 0.17 , a value similar to that found in anesthetized intact rats subjected to micropuncture $(6,7)$. Plasma potassium concentration decreased from an initial average of $5.4 \pm 0.7 \mathrm{meq} /$ liter at an average rate of $9.5 \mu \mathrm{eq} / \mathrm{min}$ as potassium was cleared by the kidney into the urine. When the concentration of potassium perfusing the kidney was gradually increased from 5 to $10 \mathrm{meq} / \mathrm{liter}$, fractional excretion of potassium rose to approach 0.7 ,

TABLE I

Potassium Excretion by Isolated Perfused Rat Kidneys

\begin{tabular}{lccc}
\hline & $\begin{array}{c}\text { Control } \\
(n=15)\end{array}$ & $P$ & $\begin{array}{c}\text { Chronically } \\
\mathrm{K}+\text { loaded } \\
(n=15)\end{array}$ \\
\hline $\mathrm{U}_{\mathrm{K}} \mathrm{V}, \mu e q / \mathrm{min}$ & $1.3 \pm 0.5$ & $<0.0005$ & $3.6 \pm 2.1$ \\
$\begin{array}{l}\text { Fractional excretion } \\
\text { of potassium }\end{array}$ & $0.41 \pm 0.17$ & $<0.0005$ & $1.41 \pm 0.44$ \\
$\begin{array}{l}\mathrm{GFR}, \mathrm{ml} / \mathrm{min} \\
\text { Fractional sodium }\end{array}$ & $0.62 \pm 0.21$ & $\mathrm{NS}$ & $0.54 \pm 0.23$ \\
$\quad$ reabsorption $\times 100$ & $93.8 \pm 3.2$ & $\mathrm{NS}$ & $95.6 \pm 2.9$
\end{tabular}

Potassium loaded rats were given a diet containing $1.74 \mathrm{meq}$ of $\mathrm{K}^{+} / \mathrm{g}$ of diet for $1 \mathrm{wk}$. Values are mean $\pm \mathrm{SD}$ at $30 \mathrm{~min}$ of perfusion. Initial perfusion medium potassium in both groups was $5.4 \pm 0.2 \mathrm{meq} /$ liter. At $30 \mathrm{~min}$ of perfusion it was $5.4 \pm 0.2$ and $4.7 \pm 0.1$ in control and potassium-loaded groups, respectively. $P$ values represent calculated probability figures between the two groups. 
TABLE II

Effect of Ouabain (4 $\mathrm{mM}$ ) on Potassium Excretion by Isolated Perfused Kidneys

\begin{tabular}{|c|c|c|c|c|}
\hline & \multicolumn{2}{|c|}{$\begin{array}{l}\text { Normal diet } \\
\quad(n=6)\end{array}$} & \multicolumn{2}{|c|}{$\begin{array}{l}\text { High-potassium diet } \\
\quad(n=5)\end{array}$} \\
\hline & Control & Ouabain & Control & Ouabain \\
\hline $\begin{array}{l}\text { Fractional excretion } \\
\text { of potassium }\end{array}$ & $0.36 \pm 0.18$ & $0.32 \pm 0.12$ & $1.27 \pm 0.52$ & $0.51 \pm 0.08 \ddagger \|$ \\
\hline $\mathrm{U} / \mathrm{P} \mathrm{K}^{+}$ & $5.72 \pm 4.01$ & $0.77 \pm 0.12 \ddagger$ & $14.33 \pm 3.92$ & $1.45 \pm 0.20 \S$ \\
\hline $\mathrm{U}_{\mathrm{K}} \mathrm{V}, \mu \mathrm{eq} / \mathrm{min}$ & $1.28 \pm 0.63$ & $0.64 \pm 0.88$ & $2.58 \pm 0.9$ & $0.96 \pm 0.14 \|$ \\
\hline $\mathrm{GFR}, \mathrm{ml} / \mathrm{min}$ & $0.70 \pm 0.26$ & $0.39 \pm 0.28$ & $0.54 \pm 0.15 \|$ & $0.38 \pm 0.06 \ddagger$ \\
\hline
\end{tabular}

Initial perfusion medium potassium was $5.8 \pm 0.2$ and $5.4 \pm 0.2$ in the normal and highpotassium diet groups, respectively.

* Values are means $\pm \mathrm{SD}$

$\ddagger P<0.05$ as compared to its own control.

\| Not significantly different from controls on a normal diet $(P<0.05)$.

but net secretion of potassium was never observed (Fig. 1).

Potassium excretion by isolated perfused kidneys from potassium-adapted rats (Table I, Fig. 2). By contrast, perfused kidneys obtained from rats chronically loaded with potassium regularly exhibited net secretion of potassium into the urine with an average fractional excretion of potassium in 15 rats of $1.41 \pm 0.44$. In no instance was fractional excretion of potassium below 1.0 , and the highest value was 3.59 . The rate of potassium excretion was $3.6 \pm 2.1 \mu \mathrm{eq} / \mathrm{min}$, and the rate at which "plasma" potassium declined as the experiment progressed was correspondingly greater than in control rats, $52.4 \mu \mathrm{eq} / \mathrm{min}$. The capacity to excrete potassium in large amounts, therefore, appeared to be an intrinsic quality of the kidney, acquired in the process of potassium adaptation, evident in the isolated organ perfused with an artificial medium entirely outside of the body of the potassium-loaded rat. Measurements of

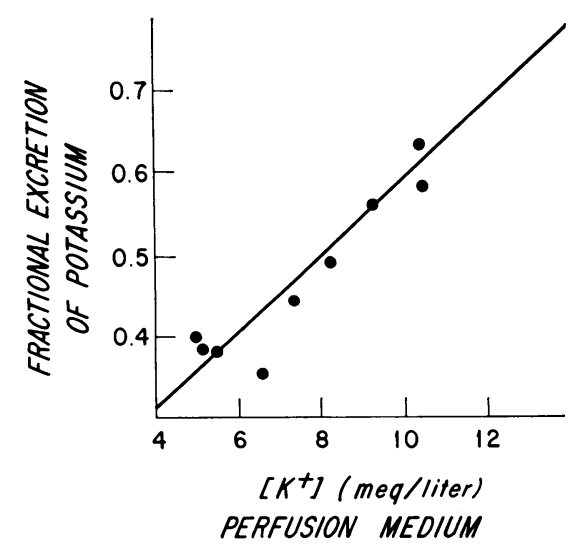

Figure 1 Effect of increasing the concentration of potassium in the perfusion medium on fractional excretion of potassium in a kidney obtained from a control rat. the potassium content of the kidney in these and in similar previous experiments with potassium loading (6) failed to show differences between normal and potassium-loaded rats.

When the concentration of potassium in the perfusion medium was progressively elevated in acute experiments, potassium excretion rose, and net secretion kept pace with the elevated plasma potassium. However, unlike the experiments with normal kidneys, fractional excretion of potassium, already elevated above 1.0, did not increase further (Fig. 2).

To elicit a secretory response in the perfused kidney, a prolonged period of prior conditioning with potassium rather than a brief exposure appears to be required. Potassium chloride, $1.2 \mathrm{meq} / \mathrm{kg}$ per $\mathrm{h}$, was infused i.v. into live rats over a period of $3 \mathrm{~h}$ before the kidneys were removed for perfusion. This maneuver did not enhance the fractional excretion of potassium in the

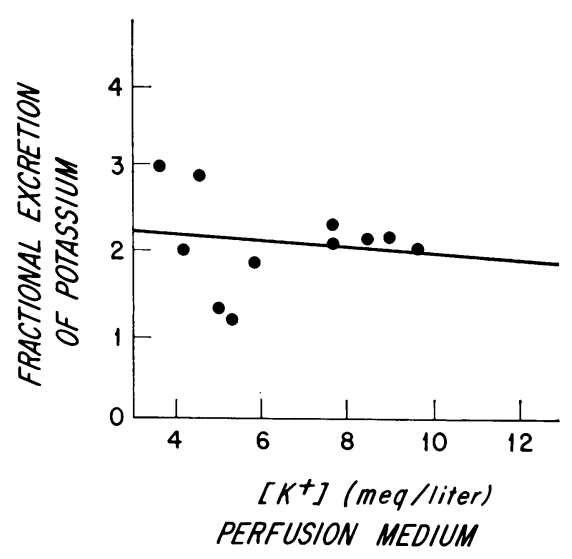

FIGURE 2 Effect of increasing the concentration of potassium in the perfusion medium on fractional excretion of potassium in a kidney obtained from a rat chronically loaded with potassium. 
TABLE III

Specific Activity of ATPase in the Papilla of the Rat Kidney

\begin{tabular}{|c|c|c|}
\hline & Na-K-ATPase & Mg ATPase \\
\hline & \multicolumn{2}{|c|}{$\mu$ mol $P i / m g$ protein $/ h$} \\
\hline $\begin{array}{l}\text { Group II, } \\
\text { potassium-loaded* }\end{array}$ & $\begin{array}{l}7.88 \pm 2.29(8) \\
4.60 \pm 1.66(6)\end{array}$ & $\begin{array}{l}23.44 \pm 4.83(8) \\
24.66 \pm 6.09(6)\end{array}$ \\
\hline $\begin{array}{l}\text { Group III, } \\
\text { methylprednisolone }\end{array}$ & $6.71 \pm 1.96(7)$ & $21.81 \pm 4.53$ \\
\hline Control & $5.33 \pm 1.73(6)$ & $24.15 \pm 4.57(6)$ \\
\hline Group IV, DOCA§ & $5.02 \pm 1.95(6)$ & $26.30 \pm 3.06(6)$ \\
\hline Control & $5.77 \pm 1.95(8)$ & $23.64 \pm 1.66(8)$ \\
\hline $\begin{array}{l}\text { Group } V, \\
\text { salt-deprived } \|\end{array}$ & $5.04 \pm 1.69(6)$ & $19.26 \pm 0.83(6)$ \\
\hline Control & $5.98 \pm 2.43(7)$ & $19.91 \pm 2.36(7)$ \\
\hline
\end{tabular}

Values are means $\pm \mathrm{SD}(n)$.

* Potassium-loaded rats received $1.74 \mathrm{meq} \mathrm{K} / \mathrm{g}$ diet/day.

$\ddagger$ Group III rats received $3 \mathrm{mg}$ methylprednisolone subcutaneously for 3 days.

§ Group IV rats received $0.5 \mathrm{mg}$ DOCA i.m. for 7 days.

$\|$ Group $\mathrm{V}$ rats were given a salt-free diet for $1 \mathrm{wk}$.

$P<0.01$, calculated vs. simultaneously run control group.

perfused kidney, nor did it alter the excretory response of the perfused kidney to subsequent progressive increments of potassium in the perfusion medium.

Role of Na-K-ATPase in potassium adaptation: the effect of ouabain (Table II). Chronic potassium loading increases the specific activity of $\mathrm{Na}-\mathrm{K}$-ATPase in the kidney (8), and it was therefore important to measure the effects of inhibition of this enzyme system with ouabain. It is possible to carry out this experiment more satisfactorily in the isolated perfused kidney since concentrations of ouabain that completely inhibit the enzyme in vitro can be added easily to the perfusion medium as extensively discussed in a previous report (3).

When $4 \mathrm{mM}$ ouabain was added to the recirculating medium, the concentration of potassium in the urine dropped sharply to equal that in the medium (Fig. 3). Fractional excretion of potassium in normal rats was not altered (because of the voluminous diuresis caused by ouabain), averaging $0.36 \pm 0.18$ before and $0.32 \pm$ 0.12 after ouabain. Net secretion of potassium by potassium-adapted kidneys, on the other hand, was sharply curtailed, fractional excretion of potassium falling from $1.27 \pm 0.52$ to $0.51 \pm 0.08$ when ouabain was added to the perfusion. The adaptive secretion of potassium by perfused kidneys, therefore, appeared to depend on the activity of Na-K-ATPase.

The effect of prior preparative maneuvers on potassium secretion by the perfused kidney. Several physiological maneuvers were next employed in an attempt to

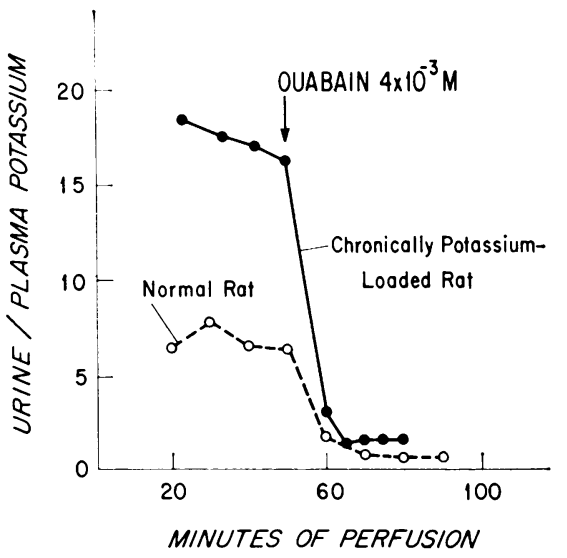

FIGLRE 3 Effect of ouabain $4 \mathrm{mM}$ on potassium excretion in kidneys obtained from a normal and a chronically potassium-loaded rat.

condition the perfused kidney to improve its ability to secrete potassium. The relation of these procedures to the specific activity of $\mathrm{Na}-\mathrm{K}-\mathrm{ATP}$ ase in various zones of the kidney was then assessed.

The effects of a sodium-free diet were of interest since sodium deprivation elicits the secretion of aldosterone, which enhances potassium excretion by the kidney (9) and also increases the specific activity of $\mathrm{Na}-\mathrm{K}-\mathrm{ATPase}$ in the renal medulla of adrenalectomized rats $(10,11)$. Sodium deprivation for $1 \mathrm{wk}$, however, did not increase the fractional excretion of potassium by perfused kidneys and did not alter the specific activity of Na-K-ATPase in cortex, outer medulla, or papilla (Fig. 4). The fractional sodium reabsorption of these perfused kidneys was significantly higher than

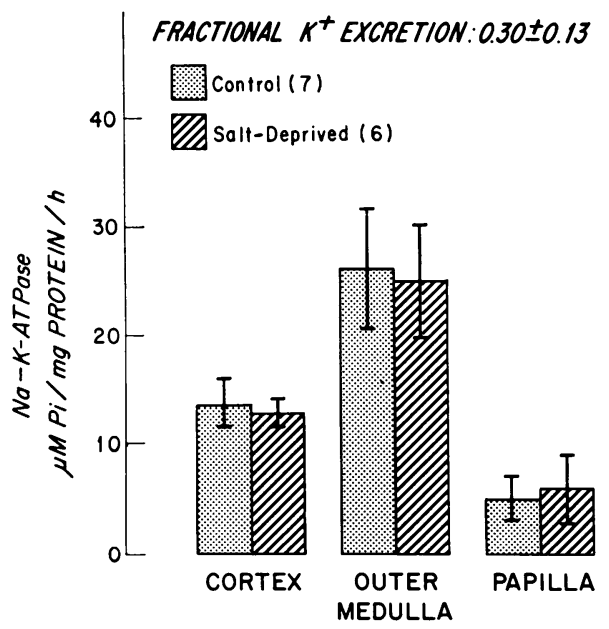

FIGURE 4 Effect of salt deprivation for 7 days on renal $\mathrm{Na}-\mathrm{K}-\mathrm{ATPase}$ specific activity. The fractional excretion of potassium in six isolated perfused kidneys of similarly prepared rats is inserted in the figure. 
TABLE IV

Potassium Excretion in Isolated Perfused Rat Kidneys: Effect of Salt Deprivation, DOCA, and Methylprednisolone

\begin{tabular}{lccc}
\hline & $\begin{array}{c}\text { Salt-deprived* } \\
(n=6)\end{array}$ & $\begin{array}{c}\text { DOCA } \\
(n=6)\end{array}$ & $\begin{array}{c}\text { Methyl- } \\
\text { prednisolone } \\
(n=6)\end{array}$ \\
\hline $\begin{array}{l}\text { (U/P K }) /(\mathrm{U} / \mathrm{P} \text { inulin }) \\
\text { GFR, } \mathrm{ml} / \mathrm{min}\end{array}$ & $0.30 \pm 0.13$ & $0.64 \pm 0.21 \|$ & $0.51 \pm 0.14$ \\
$\begin{array}{l}\text { Fractional sodium } \\
\text { reabsorption } \times 100\end{array}$ & $0.400 \pm 0.220$ & $0.668 \pm 0.120$ & $0.341 \pm 0.150 \rrbracket$ \\
\begin{tabular}{l} 
UK $\mathrm{V}, \mu e q / \mathrm{min}$ \\
\hline
\end{tabular} & $0.85 \pm 0.70$ & $2.08 \pm 0.83 \|$ & $0.92 \pm 0.40$ \\
\hline
\end{tabular}

Values are means \pm SD.

* Sodium deprivation was induced by a sodium-free diet for 7 days. Perfusion medium potassium was $50 \pm 0.3 \mathrm{meq} / \mathrm{liter}$.

$\ddagger$ DOCA was injected i.m. $50 \mathrm{~g} / 100 \mathrm{~g}$ for 7 days. Perfusion medium potassium was $48 \pm 0.2 \mathrm{meq} / \mathrm{liter}$.

\$ Methylprednisolone was injected subcutaneously $3 \mathrm{mg} / 100 \mathrm{~g}$ for 3 days. Perfusion medium potassium was $5.3 \pm 0.2 \mathrm{meq} /$ : iter.

$\| P<0.05$ calculated by $t$ test, as compared to control group in Table I

T $P<0.01$ calculated by $t$ test, as compared to control group in Table I.

that of kidneys from control rats $(97.2 \pm 3.7 \%$ vs. $93.8 \pm$ $3.2 \%$ ) (Tables III and IV).

DOCA, $0.5 \mathrm{mg} / 100 \mathrm{~g}$ body wt, was injected intramuscularly daily for 7 days into six rats. Such pretreatment elevates the specific activity of Na-K-ATPase in the renal cortex but not in the outer medulla or papilla (11). Fractional excretion of potassium was slightly increased over controls $(P<0.05)$, but net secretion of potassium was not observed, even when the concentration of potassium in the recirculating medium was increased by adding potassium chloride to the perfusion (Fig. 5 and Tables III and IV). Potassium excretion

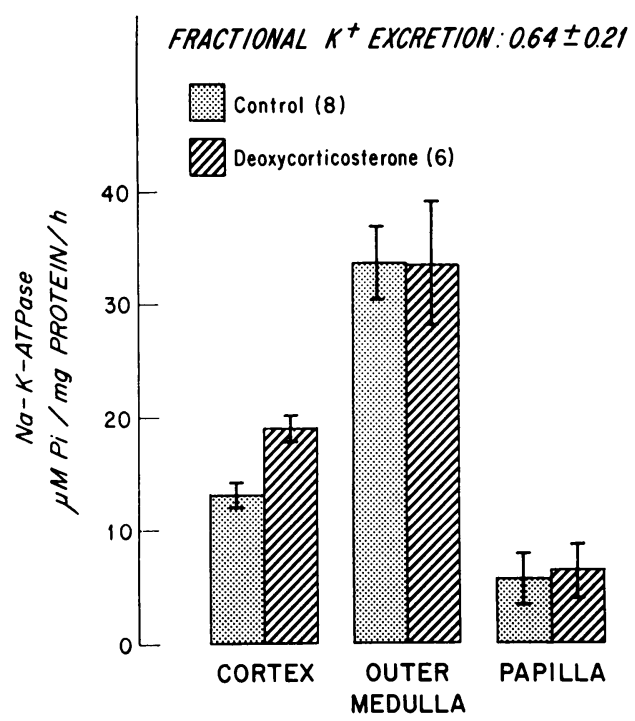

Figure 5 Effect of DOCA $0.5 \mathrm{mg} / 100 \mathrm{~g}$ per day for 7 days on renal Na-K-ATPase specific activity. The fractional excretion of potassium in six isolated perfused kidneys of similarly prepared rats is inserted in the figure.

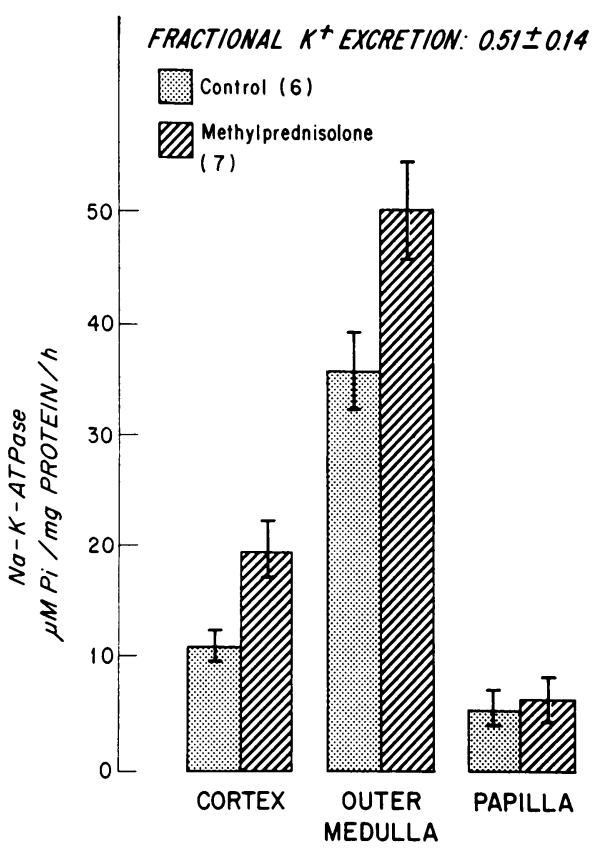

Figure 6 Effect of methylprednisolone $3 \mathrm{mg} / 100 \mathrm{~g}$ per day for 3 days on renal Na-K-ATPase specific activity. The fractional excretion of potassium in five isolated perfused kidneys obtained from similarly prepared rats is inserted in the figure.

was, nevertheless, increased in kidneys treated with DOCA because of a higher mean filtration rate, together with an increase in fractional excretion of potassium.

Methylprednisolone was injected into five rats for 3 days since glucocorticoids have been shown to increase the specific activity of Na-K-ATPase in whole homogenates of kidney cortex and outer medulla (11). Surprisingly, while cortical Na-K-ATPase rose $75 \%$ (from $11.2 \pm 1.7$ to $19.6 \pm 2.0$ ) and medullary Na-KATPase increased $42 \%$ (from $36.1 \pm 4.5$ to $51.1 \pm 5.8$ ), the specific activity of Na-K-ATPase in the papilla was unchanged by methylprednisolone. Isolated kidneys from rats pretreated with methylprednisolone did not differ from normal controls in their fractional excretion of potassium. None demonstrated net potassium secretion (Fig. 6, and Tables III and IV).

Prior loading with potassium for 7 days, as indicated above, permitted isolated perfused kidneys to secrete potassium into the urine at rates exceeding glomerular filtration. As previously recorded (8), the specific activity of Na-K-ATPase in cortex and medulla was increased by chronic potassium loading. In addition, of all the maneuvers employed, this was the only one that increased the activity of Na-K-ATPase in the white papilla as well. Enzymatic activity in this portion of the kidney rose $71 \%$, from $4.6 \pm 1.6$ to $7.9 \pm 2.3 \mu \mathrm{mol}$ $\mathrm{Pi} / \mathrm{mg}$ protein per h, $P<0.01$, after potassium loading 
(Table III and Fig. 7). Mg-ATPase was not altered in any of the zones of the kidney by any of the maneuvers tested.

The ability of the isolated kidney to secrete potassium, therefore, appeared to be correlated best with an increase of $\mathrm{Na}-\mathrm{K}-\mathrm{ATPase}$ in the white inner medulla or papillary tip of the kidney and was not induced by physiological maneuvers that enhanced Na-K-ATPase activity only in the cortex or outer medulla representing more proximal portions of the nephron.

Effect of papillectomy (Table $V$ ). The foregoing experiments suggested that the terminal collecting ducts contained in the renal papilla might be largely responsible for the net secretion of potassium characteristic of potassium adaptation. To test this hypothesis, the white papilla was surgically removed from the right kidney of seven rats 1 wk before they were placed on a high potassium diet for 7 days in preparation for isolated perfusion of the papillectomized kidney. Excision of the papilla was accomplished with a pituitary forceps inserted through a small incision in the lower pole of the kidney, a method that produced minimal scarring and damage to the remaining portions of the kidney, therefore obviating a problem that had proved troublesome in our previous attempts using the technique of papillectomy suggested by Wilson (12). Removal of the white papilla eliminated net secretion of potassium completely in six of seven perfused kidneys of potassium-loaded rats, the average fractional excretion

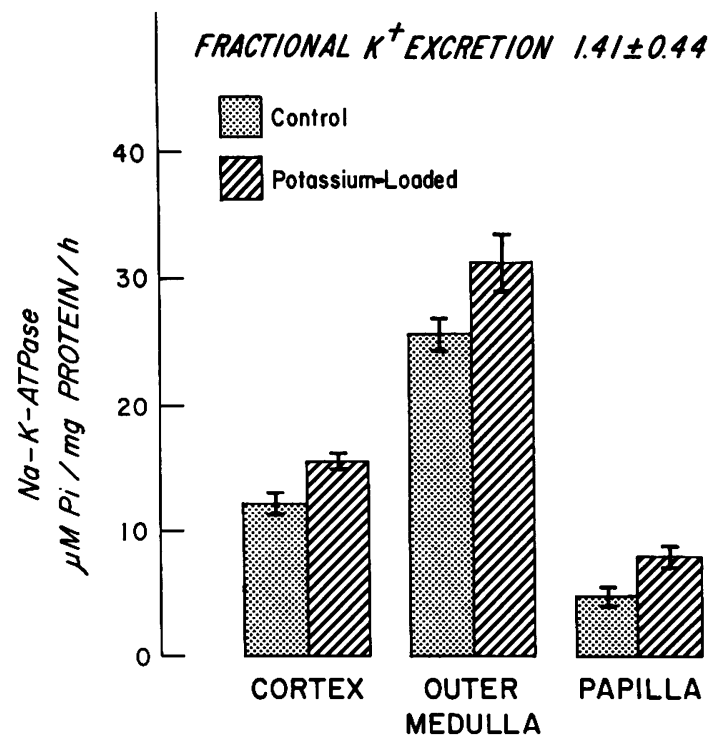

FIGURE 7 Effect of potassium loading ( $1.74 \mathrm{meq} / \mathrm{g}$ of diet) for 7 days on renal $\mathrm{Na}-\mathrm{K}-\mathrm{ATPase}$ specific activity. The number of experimental animals was 8, that of controls 6 . The average fractional excretion of potassium in 15 isolated perfused kidneys of similarly prepared animals is inserted in the figure.
TABLE V

Effecl of Papillectomy on Potassium Excretion by Isolated Perfused Rat Kidneys

\begin{tabular}{ccc}
\hline & GFR & $\begin{array}{c}\text { Fractional } \\
\text { excretion of } \\
\text { potassium }\end{array}$ \\
\hline $\begin{array}{c}\text { Normal kidneys, } \\
\text { normal diet }(n=15)\end{array}$ & $0.62 \pm 0.21$ & $0.41 \pm 0.17$ \\
$\begin{array}{c}\text { Papillectomized kidneys, } \\
\text { normal diet }(n=5)\end{array}$ & $0.20 \pm 0.07$ & $0.59 \pm 0.21$ \\
$\begin{array}{c}\text { Normal kidneys, } \\
\text { high-K diet }(n=15)\end{array}$ & $0.54 \pm 0.23$ & $1.41 \pm 0.44^{*}$ \\
$\begin{array}{c}\text { Papillectomized kidneys, } \\
\text { high-K diet }(n=7)\end{array}$ & $0.29 \pm 0.08^{*}$ & $0.63 \pm 0.35$ \\
\hline
\end{tabular}

Values are mean \pm SD.

${ }^{*} P<0.01$ when compared to control.

of potassium falling to $0.63 \pm 0.35$. Some evidence of potassium adaptation was nevertheless noted in one papillectomized kidney with a fractional potassium excretion equal to 1.38 .

\section{DISCUSSION}

The ability of animals to adapt to potassium loads so as to avoid lethal hyperkalemia has been much studied $(6,13-15)$, and although there is some argument about the existence of an extrarenal mechanism of potassium adaptation $(14,15)$, there is no doubt that the major factor is the acquired ability of the kidneys to excrete large amounts of potassium rapidly into the urine. The present experiments show clearly that such potassium adaptation resides in the kidney itself, since it can be demonstrated in the isolated organ excised from the body and perfused with an artificial medium. Kidneys from rats conditioned to a high intake of potassium regularly showed net secretion of potassium into the urine, excreting up to three times the amount of potassium filtered at the glomerulus.

It is natural to suggest that this impressive adaptation of the kidney to excrete potassium might be connected with the increase in the specific activity of $\mathrm{Na-K}-\mathrm{ATPase}$ in kidney tissue induced by a high potassium diet (8), and for this reason the effect of perfusing the potassium-adapted kidney with ouabain so as to inhibit Na-K-ATPase was studied. Strophanthidin had earlier been shown to decrease the excretion rate of potassium in the chicken kidney in which potassium excretion had been stimulated by the infusion of potassium into the renal portal vein (16). In the intact rat, on the other hand, the direct intrarenal infusion of ouabain was noted by Strieder et al. to increase the 
excretion of potassium, reducing its reabsorption in the distal tubule (17). In these experiments, however, the rats had not been subjected to potassium loads, having been prepared by feeding a diet either low or normal in potassium. Furthermore, the calculated concentration of ouabain in renal arterial blood was approximately $10 \mu \mathrm{M}$, only about $1 / 100$ of that necessary to inhibit rat kidney Na-K-ATPase completely in vitro (3). The perfused kidney preparation employed in the present experiments permitted the use of a far higher concentration of ouabain so that enzyme inhibition could be assured. In addition to provoking an intense sodium diuresis, ouabain completely eliminated net potassium secretion in kidneys from potassium-adapted rats, returning the fractional excretion of potassium close to the level characteristic of kidneys not adapted to potassium loads. The fractional excretion of potassium in normal kidneys, on the other hand, was not greatly affected by ouabain. Considerable evidence has recently been adduced to indicate that secretion of potassium into the distal tubule is directly related to the size of the intracellular pool of potassium in cells lining the tubule itself $(18,19)$. Ouabain presumably suppresses potassium secretion by inhibiting the linked sodium-potassium pump on the peritubular border of renal tubular cells lining the distal nephron, resulting in a fall in the intracellular concentration of potassium.

It was of interest to try to alter the behavior of the perfused kidney by preparative maneuvers that would change renal $\mathrm{Na}-\mathrm{K}-\mathrm{ATPase}$ or that had been reported to induce potassium tolerance. Wright and co-workers found that "moderate sodium depletion," produced by feeding rats of the Long-Evans strain a low-sodium diet for 8-12 days, improved the ability to excrete potassium, whereas severe and prolonged sodium depletion interfered with potassium tolerance (6). In the present experiments, perfused kidneys from sodiumdepleted rats showed a normal fractional excretion of potassium. A second attempt at manipulation that should induce the kidney to excrete more potassium involved pretreatment with DOCA, which was shown by Charney et al. to increase the specific activity of $\mathrm{Na}-\mathrm{K}$ ATPase in renal cortex, an effect dependent on the inclusion of sodium in the diet (11). Enzyme activities in the outer medulla and papilla of the kidney are unchanged by DOCA. The specific site within the rat nephron of the increase in Na-K-ATPase produced by DOCA injections is not clear, but there are reasons to think that it is the distal cortical tubule (11). Preparation with DOCA increased fractional excretion of potassium slightly but did not produce net potassium secretion by the perfused kidney.

Methylprednisolone greatly increases the specific activity of $\mathrm{Na}-\mathrm{K}$-ATPase in both cortex and outer medulla of the kidneys $(10,11)$, and it was therefore surprising that fractional excretion of potassium was not increased at all in perfused kidneys taken from rats pretreated with this drug. One explanation may lie in the fact that, despite large increases in enzyme activity in cortex and red medulla, $\mathrm{Na}-\mathrm{K}-\mathrm{ATPase}$ activity of the inner medulla or white papilla of the kidney remained unchanged. Potassium loading, on the other hand, did induce a substantial increase in the Na-K-ATPase of the renal papilla, and it is tempting to ascribe the increased secretory capacity of the perfused kidney to this change, though there are obviously other possible explanations.

The role of the terminal collecting ducts in potassium secretion by the rat kidney has been the subject of some controversy (20). The isolated cortical collecting duct of the rabbit has been shown capable of adding potassium to the urine (21), as has the papillary collecting duct of the hamster (22). Several studies by Malnic and Giebisch and their associates in rats, however, failed to demonstrate net addition of potassium to the urine beyond the distal convoluted tubule $(7,23)$, and Diezi et al. were unable to show net potassium secretion consistently in the papillary collecting duct of the rat (24). More recently, Bank and Aynedjian have been able to demonstrate the addition of potassium to the final urine at a point distal to the micropunctured cortical distal convolution in partially nephrectomized rats subjected to potassium loads. They suggest that secretion of potassium by the papillary collecting ducts may become especially important during potassium surfeit and in renal insufficiency (25).

The present experiments with perfused kidneys from which the papilla was excised strongly support this view. Papillectomy of the potassium-adapted kidney greatly reduced the fractional excretion of potassium, which fell from an average of 1.41 to 0.63 . Net secretion of potassium was eliminated in six of seven kidneys. Papillectomy may not have erased all evidence of potassium adaptation, since the excretion of potassium after papillectomy exceeded the amount filtered in one kidney taken from a potassium-adapted rat. While it seems likely that potassium secretion by distal convoluted tubules and cortical collecting ducts contributes to potassium adaptation, these results suggest that a critical part must be played by the terminal collecting ducts of the white papilla, which add potassium to the urine and make it possible for the adapted kidney to excrete potassium in excess of the amount filtered.

\section{ACKNOWLEDGMENTS}

The technical assistance of Mrs. Deborah Perlman, Miss Katherine Spokes, and Mr. Michael Mishkind is gratefully acknowledged.

Data analysis was performed on PROPHET, sponsored by the Chemical/Biological Information Handling Program, 
National Institutes of Health. This work was supported in part by a grant (RR-76) from General Clinical Research Centers Program of the Division of Research Resources, National Institutes of Health, and aided by Grant AM 18078 from the U. S. Public Health Services.

\section{REFERENCES}

1. Ross, B. D., F. H. Epstein, and A. Leaf. 1973. Sodium reabsorption in the perfused rat kidney. Am. J. Physiol. 225: $1165-1171$.

2. Nishiitsutsuji-Uwo, J. M., B. D. Ross, and H. A. Krebs. 1967. Metabolic activities of the isolated perfused rat kidney. Biochcm. J. 103: 852-862.

3. Ross, B., A. Leaf, P. Silva, and F. H. Epstein. 1974. Na-K-ATPase in sodium transport by the perfused rat kidney. Am. J. Physiol. 226: 624-629.

4. Fiske, C. H., and Y. SubbaRow. 1925. The colorimetric determination of phosphorus. J. Biol. Chem. 66: 375400 .

5. Lowry, O. H., N. J. Rosebrough, A. L. Farr, and R. J. Randall. 1951. Protein measurement with the Folin phenol reagent. J. Biol. Chem. 193: 265-275.

6. Wright, F. S., N. Strieder, N. B. Fowler, and G. Giebisch. 1971. Potassium secretion by distal tubule after potassium adaptation. Am. J. Physiol. 221: 437448.

7. Malnic, G., M. de Mello Aires, and G. Giebisch. 1971. Potassium transport across renal distal tubules during acid-base disturbances. Am. J. Physiol. 221: 1192-1208.

8. Silva, P., J. P. Hayslett, and F. H. Epstein. 1973. The role of $\mathrm{Na}-\mathrm{K}$-activated adenosine triphosphatase in potassium adaptation. Stimulation of enzymatic activity by potassium loading. J. Clin. Invest. 52: 26652671.

9. Boyd, J. E., W. P. Palmore, and P. J. Mulrow. 1971. Role of potassium in the control of aldosterone secretion in the rat. Endocrinology. 88: 556-565.

10. Hendler, E. D., J. Torretti, L. Kupor, and F. H. Epstein. 1972. Effects of adrenalectomy and hormone replacement on Na-K-ATPase in renal tissue. $\mathrm{Am}$. J. Physiol. 222 : 754-760.

11. Charney, A. N., P. Silva, A. Besarab, and F. H. Epstein. 1974. Separate effects of aldosterone, DOCA, and methylprednisolone on renal Na-K-ATPase. Am. J. Physiol. 227 : 345-350.
12. Wilson, D. R. 1972. The effect of papillectomy on renal function in the rat during hydropenia and after an acute saline load. Can. J. Phy'siol. Pharmacol. 50: 662673.

13. Thatcher, J. S., and A. W. Radike. 1947. Tolerance to potassium intoxication in the albino rat. Am. J. Physiol. $151: 138-146$.

14. Alexander, E. A., and N. G. Levinsky. 1968. An extrarenal mechanism of potassium adaptation. J. Clin. Invest. $47:$ 740-748.

15. Adam, W. R., and J. K. Dawborn. 1972. Potassium tolerance in rats. Aust. J. Exp. Biol. Med. Sci. 50: 757-768.

16. Orloff, J., and M. Burg. 1960. Effect of strophanthidin on electrolyte excretion in the chicken. Am. J. Physiol. 199: 49-54.

17. Strieder, N., R. Khuri, M. Wiederholt, and G. Giebisch. 1974. Studies on the renal action of ouabain in the rat. Effects in the non-diuretic state. Pfliigers Arch. Eur. J. Physiol. 349: 91-107.

18. Khuri, R. N., S. K. Agulian, and A. Kalloghlian. 1972. Intracellular potassium in cells of the distal tubule. Pfiügers Arch. Eur. J. Physiol. 335: 297-308.

19. de Mello-Aires, M. G. Giebisch, and G. Malnic. 1973. Kinetics of potassium transport across single distal tubules of rat kidney. J. Physiol. (Lond.). 232: 47-70.

20. Stein, J. H., and H. J. Reineck. 1974. The role of the collecting duct in the regulation of excretion of sodium and other electrolytes. Kidney Int. 6: 1-9.

21. Grantham, J. J., M. B. Burg, and J. Orloff. 1970. The nature of transtubular $\mathrm{Na}$ and $\mathrm{K}$ transport in isolated rabbit renal collecting tubules. J. Clin. Inv'est. 49: 18151926.

22. Hierholzer, K. 1961. Secretion of potassium and acidification in collecting duct of mammalian kidney. Am. J. Physiol. 201 : 318-324.

23. Malnic, G., R. M. Klose, and G. Giebisch. 1964. Micropuncture study of renal potassium excretion in the rat. Am. J. Physiol. 206: 674-686.

24. Diezi, J., P. Michoud, J. Aceves, and G. Giebisch. 1973. Micropuncture study of electrolyte transport across papillary collecting duct of the rat. Am. J. Physiol. 224: 623-634.

25. Bank, N., and H. Aynedjian. 1973. A micropuncture study of potassium excretion by the remnant kidney. $J$. Clin. Invest. 52 : 1480-1490. 